\title{
Intizar
}

Vol. 25, No. 1, Juni 2019

Website: http://jurnal.radenfatah.ac.id/index.php/intizar

ISSN 1412-1697, e-ISSN 2477-3816

\section{Strategi Adaptasi dan Pertahanan Jemaat Ahmadiyah Indonesia di Kudus Jawa Tengah}

\author{
Moh Rosyid \\ IAIN Kudus, Indonesia, mrosyid72@yahoo.co.id \\ DOI: https://doi.org/10.19109/intizar.v25i1.3277
}

\begin{abstract}
Abstrak
Penelitian ini bertujuan untuk mengetahui strategi adaptasi dan pertahanan Jemaat Ahmadiyah Indonesia (JAI) di Kudus Jawa Tengah sejak tahun 1999 hingga kini. Metode penelitian yang digunakan adalah penelitian kualitatif dengan deskriptif analitis. Data diperoleh melalui wawancara dan observasi. Hasil penelitian menyimpulkan bahwa keberadaan JAI tidak terjadi konflik terbuka di Kudus dikarenakan pertama, kehidupan di pedesaan yang lebih mengutamakan aspek pertemanan dan persaudaraan. Kedua, warga JAI di Kudus tidak melanggar norma susila, hokum, agama, dan negara. Ketiga, ajaran Ahmadiyah tidak dipublikasikan pada warga, hanya pada intern JAI. Keempat, warga JAI melakukan adaptasi budaya dengan lingkungannya. Adapun faktor tetap eksisnya JAI di Kudus karena pertama, peran sesepuh JAI yang ekonominya di kelas menengah atas sehingga disegani warga sekitar. Kedua, adanya mubalig JAI ditugaskan dari JAI Pusat yang sehari-harinya melayani warga JAI Kudus. Ketiga, fanatikme warga JAI terhadap ajaran Ahmadiyah.
\end{abstract}

Kata Kunci: Ahmadiyah, Berkesinambungan, Nirkonflik, Tindakan Preventif

\begin{abstract}
This study aims to determine the adaptation and defense strategies of the Indonesian Ahmadiyah Congregation (JAI) in Kudus, Central Java since 1999 until now. The research method used is qualitative research with analytical descriptive. Data obtained through interviews and observations. The results of the study concluded that the existence of JAI did not occur open conflict in Kudus because first, rural life prioritizes aspects of friendship and brotherhood. Second, JAI residents in Kudus do not violate moral, legal, religious and state norms. Third, the teachings of Ahmadiyah are not made public, only on JAI internals. Fourth, JAI residents adapt their culture to their environment. The factor remains the existence of JAI in Kudus because first, the role of JAI elders whose economy is in the upper middle class is respected by local residents. Second, there are JAI missionaries assigned from the Central JAI who daily serve JAI Kudus residents. Third, JAI's fanaticism towards the Ahmadiyah teachings.
\end{abstract}

Keywords: Ahmadiyah, Sustainability, Non-Conflict, Preventive Actions

\section{Pendahuluan}

Sekte dalam agama selalu menarik ditelaah, salah satunya Ahmadiyah. Bahkan keberadaannya direspon negatif oleh pemerintah. Pernyataan Menteri Agama Suryadharma Ali saat itu memberikan alternatif pada Jemaat Ahmadiyah Indonesia (JAI) yakni menjadi sekte tersendiri menanggalkan atribut Islam, kembali pada Islam, dibiarkan hidup, dibubarkan, menjadi aliran kepercayaan atau agama baru karena keberadaannya dianggap bisul dan sasaran konflik. Selama 20072009 terjadi 300 tindak kekerasan terhadap Ahmadiyah (Tegal, 2011). Peluang menjadi agama baru bagi JAI berdalih pemerintah tak akan melarang kebebasan beragama selama berdiri sendiri dan tidak menciderai agama lain, mungkinkah meski ada pijakan hukumnya? Kata kunci konflik tertuju pada Ahmadiyah karena Ghulam Ahmad diyakini sebagai nabi sehingga dianggap sesat. Meskipun demikian, eksistensi JAI berkembang hingga di Kudus Jawa Tengah yang mengandalkan dua faktor yakni Islam abangan dan hanya didominasi oleh satu keluarga, meskipun tidak semua anggota keluarga dalam satu kepala keluarga (KK) JAI menjadi anggota JAI. Di Indonesia terdapat dua kelompok Ahmadiyah, yakni JAI Jemaat Ahmadiyah Indonesia (JAI) dan Gerakan 
Ahmadiyah Indonesia (GAI). Perbedaan prinsip keduanya, Ghulam Ahmad bagi JAI sebagai nabi sehingga dinyatakan sesat. Bagi GAI, Ghulam sebagai pembaru (mujadid) sehingga tidak dinyatakan sesat. Artikel ini mendalami JAI di Kudus yang memiliki komunitas, sedangkan GAI di Kudus hanya satu keluarga. JAI di Kudus eksis meski minoritas jumlahnya, mengapa nirkonflik dengan muslim lainnya di Kudus? Riset ini bertujuan mendalaminya.

Musyawarah Nasional (Munas) dan Konferensi Besar (Konbes) Nahdlatul Ulama (NU) di Ponpes Miftahul Huda al-Azhar di Citangkolo, Kabupaten Banjar, Jawa Barat. Munas dibuka Presiden Jokowi pada Rabu 27 Februari dan ditutup oleh Wapres Jusuf Kalla Jumat 29 Februari 2019. Hasil Munas dan Konbes merekomendasikan di antaranya, pertama, istilah kafir tidak dikenal dalam sistem kewarganegaraan di Indonesia, setiap warga negara memiliki hak yang sama di hadapan hukum maka yang ada adalah istilah non-muslim, bukan kafir. Istilah kafir berlaku ketika Nabi Saw di Makkah untuk menyebut orang yang menyembah berhala, tidak memiliki kitab suci dan agama. Tatkala Nabi hijrah ke Madinah, tidak ada istilah kafir bagi warga Madinah. Kedua, berdasarkan konstitusi RI, tidak boleh ada lembaga yang memproduk fatwa kecuali Mahkamah Agung. Sebab, Indonesia bukan negara agama sehingga tidak ada Darul Fatwa. Berbeda dengan negara di Timur Tengah dikenal sebagai negara agama maka dikenal mufti. Walau demikian, di Indonesia tidak diperbolehkan warganya tak beragama, sehingga ada Kementerian Agama. Dengan demikian, tak satu pun lembaga di Indonesia yang mengatasnamakan dirinya sebagai mufti.

Dengan rekomendasi tersebut, menelaah tentang JAI yang difatwa sesat Majelis Ulama Indonesia (MUI) menjadi hal yang menarik, meski fatwa jauh sebelum rekomendasi Munas NU Februari 2019.

\section{Metode Penelitian}

Metode penelitian yang digunakan adalah penelitian kualitatif dengan deskriptif analitis. Data penelitian ini diperoleh secara alami melalui wawancara dengan warga JAI, non-JAI, tokoh JAI di Kudus. Penggalian data juga diperoleh dengan observasi di lokasi riset. Data dianalisis secara deskriptif kualitatif agar dapat terungkap secara luaspadat berdasarkan fakta.

\section{Hasil Penelitian dan Pembahasan}

\section{Awal Kehadiran Ahmadiyah di Indonesia}

Ahmadiyah hadir di Indonesia sejak 1923. Pasca-kolonial, Ahmadiyah menjadi sasaran kerusuhan berbasis agama tingkat akar rumput. Periode 1950-an merupakan periode perkembangan yang cepat sekaligus periode pahit bagi Ahmadiyah di Indonesia. Aksi DI/TII membantai beberapa orang Ahmadiyah di Jawa Barat. Pada 1953, pemerintah mengesahkan Ahmadiyah Qadian berbadan hukum berdasarkan Surah Keputusan Menteri Kehakiman RI Nomor JA 5/23/13 tanggal 13 Maret 1953. Kehadiran Ahmadiyah di Indonesia awalnya diprakarsai tiga pemuda yang berusia 16 s.d 20 tahun, yakni Abu Bakar Ayyub, Ahmad Nuruddin, dan Zaini Dahlan berasal dari Minangkabau, Padang, Sumatera Barat yang tergabung dalam Sumatera Thawalib. Atas saran guru ketiga pemuda tersebut, Zaenuddin Labai El-Junusi dan Syekh Ibrahim Musa Paraek, semula mereka ingin belajar ke Universitas Al-Azhar Mesir, tetapi diarahkan ke Hindustan, India. Pertimbangannya, Hindustan adalah pusat reformasi dan modernisasi Islam dan banyaknya perguruan tinggi dan tokoh Islam yang berkualitas. Bagaimana bila dibandingkan dengan Al-Azhar di Mesir? Bila demikian, penulis berhipotesa bahwa upaya menggait calon santri/siswa dari berbagai penjuru sudah dilakukan oleh Ahmadiyah, termasuk Indonesia. Upaya strategis ini belum banyak data tentang Zaenuddin dan Ibrahim yang diperoleh penulis. Setelah di Hindustan, mereka bertiga melanjutkan perjalanan ke Kota Lahore selanjutnya hijrah ke Qadian. Pada 1923, ketiga santri dibaiat oleh khalifah pertama Ahmadiyah India, Hadhrat Hafiz H. Hakim. Selanjutnya, mereka bertiga pulang ke tanah air sekaligus menyiarkan Ahmadiyah di kota kelahirannya. Agar masyarakat yakin atas keberadaan Ahmadiyah, ketiga santri menghadirkan mubalig dari India, Maulana Rahmat Ali untuk tablig di Padang. Pada 1924 mubalig Ahmadiyah asal Lahore, Mirza Wali Ahmad Baig dan Maulana Ahmad datang ke kota Yogyakarta. Sekretaris Muhammadiyah Yogyakarta, Minhadjurrahman 
Djojosoegito, mengundang Mirza dan Maulana berpidato pada muktamar ke-13 Muhammadiyah. Akan tetapi, pada 1929 muktamar Muhammadiyah ke-18 di Kota Solo, disepakati oleh forum muktamar bahwa orang yang percaya ada nabi sesudah Nabi Muhammad Saw adalah kafir. Fatwa itulah, Djojosoegito meninggalkan Muhammadiyah dan membentuk gerakan Ahmadiyah Indonesia pada 4 April 1930. Pada 1953, Ahmadiyah berbadan hukum berdasarkan surah keputusan Menteri Kehakiman Nomor: JA. 5/23/13 tanggal 13 Maret 1953 (Zara, 2007).

Abad ke-20 merupakan ajang berseminya aliran dan gerakan Islam di Indonesia, di antaranya alJam'iyyah al-Khayriyah (Jami'at al-Khayr) berdiri pada 17 Juli 1905 di Jakarta, Jam'iyyatul Islah wal Irsyadil Arabi (al-Irsyad) berdiri pada 11 Agustus 1915 di Jakarta, Muhammadiyah berdiri pada 12 November 1912 di Yogyakarta, Syarikat Islam (SI) berdiri tahun 1913, Nahdlatul Ulama berdiri 31 Januari 1926, dan Persis berdiri 12 September 1923 di Bandung. Bila dipetakan, masing-masing memiliki massa dan basis sendiri-sendiri. Akan tetapi, di antara arus bawah, kadang mudah tersulut percikan api karena fanatikme sempit (Rosyid, 2015).

Pada 1950-1970 banyaknya tokoh negara yang akrab dengan Ahmadiyah, meski pada 1974 MUI memfatwa sesat Ahmadiyah. Pada 1999 saat Abdurrahman Wahid menjadi Presiden RI, Ahmadiyah seakan-akan mendapat bapak asuh (Gus Dur). Didukung peran Moslem Television Ahmadiyyah (MTA) hasil pencanangan program Baiat Internasionalnya. Pada 2000, warga Ahmadiyah berhasil mendatangkan pemimpin tertingginya yang bermarkas di London, Hadhrat Mirza Tahir Ahmad ke Indonesia. Mirza bertemu dengan Presiden Gus Dur dan Ketua MPR Amien Rais. Pada 2005, MUI menegaskan lagi dengan fatwa sesat pada Ahmadiyah sehingga banyak masjid dan warga JAI di Indonesia yang menderita serangan dari warga non-JAI. Selanjutnya terbitlah Surah Keputusan Bersama (SKB) 3 menteri yang membatasi ruang gerak JAI dan semakin terdorong pada killing zone (Ahmad, 2013).

Pada era Orde Lama dan Orde Baru (boleh dinyatakan) tidak pernah terjadi konflik fisik antara
JAI dengan pihak lain hingga menimbulkan korban nyawa. Bukan berarti nihil konflik karena kedua era itu, peran media tidak sebebas era setelahnya atau terbatasnya kuantitas dan kualitas media massa. Sehingga wacana yang mengemuka adalah sering terjadi perdebatan JAI dengan muslimin, tetapi tidak anarkis. Baru di era Reformasi terjadi tindak kekerasan terhadap JAI. Secara garis besar ada 3 masalah utama yang dihadapi JAI (1) menodai Islam sehingga pemerintah harus membubarkannya berdasarkan UU Nomor 1/PNPS/1965. Aktivis HAM menyatakan bahwa pembubaran tidak sesuai dengan UUD yang mengandung substansi HAM. Ada pula yang mengusulkan agar JAI diperlakukan sebagaimana di Pakistan sehingga pemerintah menyatakan Ahmadiyah bukan Islam. Rupanya yang mengusulkan lupa bahwa Pakistan adalah negara Islam dan Indonesia berdasar Pancasila, (2) warga JAI mempunyai hak hidup di Indonesia dan tidak boleh dibubarkan atau dibatasi kegiatannya perspektif pegiat HAM. Di sisi lain, pemerintah mengeluarkan SKB yang kurang sosialisasi, (3) dan perlindungam terhadap keamanan warga JAI dan hartanya adalah kewajiban negara (Wahid, 2011).

Jemaat Ahmadiyah di Indonesia dibagi menjadi dua yakni Ahmadiyah Lahor (Gerakan Ahmadiyah Indonesia/GAI) dan Ahmadiyah Qadian (Jemaat Ahmadiyah Indonesia/JAI). JAI berbadan hukum berdasarkan Keputusan Menteri Kehakiman RI Nomor 5/23/1953 tanggal 13 Maret 1953. Di desa Colo Kudus mengikuti JAI (Ahmadiyah Qadian). JAI memiliki moto yaitu Love for all hatred for none, humanity first (cinta untuk semua, tidak ada kebencian bagi siapa pun, kemanusiaan yang utama) dan taat pada instruksi/perintah/himbauan pada pimpinan. Keberadaan JAI Kudus yang didominasi oleh satu ikatan keluarga, ada pula dari tetangga dan mitra kerja. Akan tetapi, di antara tetangga tersebut kembali ke NU dengan dalih ajaran dalam Ahmadiyah ada yang berbeda dengan pemahamannya dalam NU (sebelum menjadi Ahmadiyah) yakni tidak mentradisikan berziarah dan tidak merayakan ulang tahun wafat tiap tahun (haul) Sunan Muria, anggota Walisongo. Hal ini karena Ahmadiyah mengajarkan purifikasi Islam, sehingga hal-hal yang beraroma budaya yang terakulturasi dalam keagamaan tidak diajarkannya. 
Hal utama pemicu ketegangan JAI Kudus dengan warga NU setempat pertama, jemaat JAI menyendiri dalam berkegiatan keagamaan yakni organisasi di kampung dengan membaca surah Yasin bergantian di rumah tiap anggota. Semula, organisasi tersebut membaur dengan NU. Hal ini akibat kekalahan pilihan dalam pilkades. Pemicu awalnya, sang pemenang pilkades yang juga pemimpin jemaah Yasinan (sebelum hari $\mathrm{H}$ pilkades) tim suksesnya menyatakan bahwa bagi warga Desa Colo yang pernah mengaji dengan sang kiai (kontestan Pilkades) agar ikut memenangkannya. Tetapi, tokoh (yang selanjutnya menjadi tokoh JAI Kudus) memiliki pilihan lain karena kedekatan pertemanan. Kedua, dengan dimenangkannya sang kiai maka mereka memiliki 'kewenangan' untuk mendiskriminasikan lawan dengan ragam dalih. Ketiga, konflik kian memuncak berupa ketegangan urat syaraf dua kelompok (NU Vs JAI) yang dipicu (1) makin bertambahnya jumlah JAI di Desa Colo, (2) dibangunnya Masjid Ahmadiyah di Desa Colo yang memanfaatkan sebidang tanah milik tokoh JAI Kudus, (3) aktifnya pertemuan rutin warga JAI Kudus karena keberadaan mubalig JAI yang bermukim di Desa Colo dari utusan Kantor Pusat JAI di Parung Bogor hingga kini. Akan tetapi, seiring dengan waktu, ada pula warga JAI yang tidak aktif lagi di JAI karena ragam persoalan, seperti tidak akomodatifnya ajaran JAI terhadap tradisi lokal (seperti haul), ada pula yang meninggal dunia dan keluarganya tak ada yang mengikuti jejaknya dalam JAI. Dengan demikian muncul persoalan, seperti apakah mata rantai yang menyebabkan bertahannya JAI di Kudus?.

\section{Jejak Pelarangan JAI di Indonesia}

Ada dua konsep kenabian dalam Ahmadiyah. Pertama, JAI beranggapan Nabi Saw wafat, muncul nabi lain hingga kiamat (nabi buruzi) yakni nabi yang tidak membawa syariat. Kenabiannya dipilah (1) Nabi Shahib asy-Syari'ah, nabi pembawa syariat (hukum) untuk manusia. Nabi Mustaqil (hamba Allah menjadi nabi tidak mengikuti nabi sebelumnya) seperti Nabi Musa, (2) Nabi Mustaqil Ghair at-Tasyri'i yakni hamba Tuhan menjadi nabi tidak mengikuti nabi sebelumnya, tidak membawa syariat baru, ditugasi Allah menjalankan syariat nabi sebelumnya, seperti Nabi Harun, Daud, Sulaiman, Zakaria, Yahya, dan Isa AS, (3) Nabi Zhilli Ghair atTasyri' $i$ (hamba Tuhan dianugerahi-Nya menjadi nabi karena patuh pada nabi sebelumnya dan mengikuti syariat nabi sebelumnya, tingkatannya di bawah kenabian sebelumnya dan tidak membawa syariat baru. Ungkapan Ghulam yang dikutip oleh Ahmad dalam Tajalliyat-Ilahiyah bahwa hanya nabi yang membawa syariat saja yang sudah berakhir karena lembaga kenabian telah tertutup. Nabi yang tidak membawa syariat akan terus berlangsung.

Kedua, Gerakan Ahmadiyah Lahore Indonesia (GAI) berpandangan bahwa Nabi Saw nabi terakhir, tidak akan ada nabi lagi, Mirza bukan nabi tetapi mempunyai persamaan dengan nabi karena menerima wahyu yang tidak tasyri'i (mengikuti syariat nabi sebelumnya, tingkatannya di bawah kenabian sebelumnya dan tidak membawa syariat baru). Ghulam sebagai pendiri Ahmadiyah dan pembaru (mujadid) abad ke-14 H, wafat 1908 disebut muhaddats (penerima firman Ilahi) karena wahyu sebagai kenikmatan dianugerahkan pada nabi yang disebut nabi hakiki (pembawa syariat) dan nabi lughowi/majazi/tidak hakiki (menerima wahyu, sama dengan nabi) (Zulkarnain, 2005). Kepemimpinan Ghulam diteruskan Hakim Nuruddin hingga tahun 1914, dilanjutkan Basyiruddin Mahmud Ahmad, putra Hazrat Mirza. Kelompok yang tidak sepakat pengangkatan Basyiruddin sebagai khalifah memisahkan menjadi Ahmadiyah Lahore, di Indonesia menjadi Gerakan Ahmadiyah Indonesia (GAI). Versi lain, munculnya Ahmadiyah Lahore berawal dari isu kenabian Mirza ketika Ahmadiyah dipimpin Hakim Nuruddin (khalifah Mahdi pertama). Setelah wafat, Maulana Rahmad Ali menyelamatkan Ahmadiyah tetapi gagal karena yang terpilih sebagai khalifah kedua Mirza Ghulam Ahmad. Dengan gagalnya Maulana sebagai khalifah, ia bertekad membentuk organisasi baru yakni Ahmadiyah Lahore yang berpandangan bahwa Mirza Ghulam sebagai mujadid (pembaru), bukan nabi. Berbeda dengan Ahmadiyah Qadian bahwa ada tiga klasifikasi nabi pertama, nabi shahib as-syariah dan mustaqil yakni nabi yang membawa syariat sebagaimana Musa dan Muhammad Saw. Kedua, nabi mustaqil ghairu at-tasyri yakni nabi yang tidak mengikuti nabi sebelumnya, ia diutus berdiri sendiri, 
hanya saja tidak membawa syariat dari Allah, seperti Nabi Harun, Dawud, Sulaiman, Zakaria, Yahya, dan Isa. Ketiga, nabi zhilli ghairi at-tasyri' yakni nabi yang dianugerahi Tuhan karena kepatuhannya menjalankan ajaran nabi sebelumnya. Ia tidak membawa syariat baru dan tingkatannya di bawah nabi sebelumnya, dialah Ghulam Ahmad dalam JAI (Hasbiyallah \& Syarifudin, 2008).

Sejak tahun 1916 pelarangan terhadap Ahmadiyah karena kesesatan Ahmadiyah dilakukan di India oleh Syeikh Muhammad Husein alBattalawi, Maulana Muhammad Ali al-Monkiri (pendiri Nadwatul Ulama India), Syeikh Thana'ullah al-Amritsari, Syeikh Anwar Shah al-Kashmiri, dan Seyyed Ata'ullah al-Bukhari al-Amritsari, dan Muhammad Iqbal. Mereka menyeru kolonial Inggris di India menghentikan fitnah karena Ahmadiyah/Qadiyan sebagai upaya sistematis mendirikan golongan baru di atas dasar kenabian yang menandingi kenabian Muhammad Saw. Tetapi seruan tersebut tidak dihiraukan. Bahkan Menlu Pakistan (berhaluan Ahmadiyah) Zafarullah Khan, membangun jaringan Ahmadiyah nasional dan internasional. Tahun 1953 terpicu demonstrasi besar di Pakistan dan diperkuat pertemuan di Karachi yang dihadiri partai dan organisasi Islam yang melahirkan resolusi bahwa Mirza dan komunitas Ahmadiyah bukan muslim. Pada 7 September 1974 resolusi Majelis Nasional Pakistan memutuskan penolakan terhadap Ahmadiyah.

Latar belakang didirikannya Ahmadiyah karena upaya Inggris memecah belah muslim di India. Perspektif non-Ahmadi, kelahiran Ahmadiyah tidak dapat dipisahkan dengan gerakan orientalisme dan kolonialisme di Asia Selatan khususnya India. Tokoh orientalis Sayyid Ahmad Khan menyatakan bahwa akhir abad ke-19 Inggris memprakondisikan masyarakat India dihadapkan dengan gagasan yang menyimpang Islam. Kolonial Inggris mengadu domba masyarakat sehingga pada 23 Maret 1889 didirikan Ahmadiyah. Agar gerakannya mendapat wibawa, ditunjuklah keluarga bangsawan India keturunan Kerajaan Moghul, putra pasangan Mirza Ghulam Murtadha dengan Ciragh Bibi, yakni Mirza Ghulam Ahmad (1839-1908). Nenek moyangnya berhubungan keluarga dengan Zahiruddin Muhammad Babur, pendiri Dinasti Moghul (1526-
1530). Ayahnya seorang hakim pemerintah kolonial Inggris di India. Para komandan dan pemimpin imperialis Inggris berkumpul di London dan menggagas berbagai rencana untuk melawan Islam. Upayanya dengan memecah-belah yakni mendirikan aliran sesat dan merusak dasar-dasar Islam maka terbentuklah Ahmadiyah. Ahmadiyah menyokong Inggris berupa fatwa bahwa muslim tidak boleh mengangkat senjata melawan Inggris karena jihad sudah ditiadakan. Selanjutnya ditegaskan, orang Inggris adalah para khalifah Allah di muka bumi (Dzahir \& Dahri, 2008). Berkenaan dengan tuduhan bahwa Ahmadiyah adalah kaki tangan Inggris dan didirikannya Ahmadiyah untuk memecah belah umat Islam, JAI menegaskan bahwa umat Islam saat itu telah terpecah belah. Bahkan Mirza menulis buku yang isinya untuk meruntuhkan asas trinitas dalam ajaran kristiani, yakni agama yang dipeluk mayoritas warga Inggris. Dengan demikian, tidak logis bagi Inggris mengangkat nabi pada sosok yang telah meruntuhkan sendi trinitas. London sebagai pusat Ahmadiyah (JAI) dunia berimbas terhadap dugaan bahwa hingga kini, Inggris sebagai pemasok dana aktivitas Ahmadiyah, meski perlu diperkuat dengan data riil. Oleh JAI, tidak ada bukti bahwa pendanaan Ahmadiyah berasal dari Inggris (Penyusun, 2012).

Menjelang berdirinya Ahmadiyah di India, suasana India dalam kondisi instabil. Pada 1857 India sebagai pusat konflik imbas pemahaman tradisional dan modern, perang saudara antar-sekte, dan ketegangan Islam dengan Kristen yang memuncak. Di saat yang sama diwacanakan akan muncul sosok Imam Mahdi, dewa penyelamat. Mirza Ghulam menemui situasi yang tepat karena hadir di tengah kegelisahan batin dan keputusasaan masyarakatnya yang dilampiaskan dalam bentuk mistik. Pemerintahan Inggris menyongsong Ahmadiyah dengan suka cita karena Ghulam memiliki hubungan dekat dengan Inggris (Nadwi, Mundzir, \& Ranam, 2005). Sebelum bangsa Inggris datang di India, sebagian daerah Hindustan dikuasai bangsa Sikh dan muslim India diperlakukan tidak arif oleh Sikh sehingga menderita. Kemerdekaan beragama dan kebebasan berdakwah itulah Mirza Ghulam memuji Inggris, sebagaimana dilakukan ulama besar non-Ahmadi, antara lain Sayyid Ahmad Bhrelwi (mujadid dan mujahid abad ke-13), Syed Ali 
al-Hariri (ulama Syiah di Hindustan), dan Syekh Muhammad Abduh (Sulaeman \& Sabandi, 2014). Kedekatan Ahmadiyah dengan Inggris memunculkan anggapan bahwa Inggris berperan sebagai sponsor pendanaan Ahmadiyah. Bila tidak, lantas sumber dana organisasi dari mana? JAI berdalih memiliki aset yang dapat dijadikan sumber organisasi yakni pemenuhan kewajiban jemaat dalam zakat mal (candah). Besaran sumber dana ini dapatkah memenuhi semua pembiayaan JAI ?

Menurut Ali Mustafa Yaqub (alm), mantan Imam Masjid Istiqlal Jakarta, Ahmadiyah ngoplos (mencampur penafsiran) ayat dalam al-Baqarah: 35 tentang perintah Allah swt agar Adam tinggal di surga. Kata 'Ya Adam' diganti 'Ya Ahmad'. AlAnfal: 17 oleh Ahmadiyah maknanya adalah "Ya Ahmad, Kami mengutus engkau dari Qadian, bukan kamu yang melempar ketika kamu melempar, tetapi Allahlah yang melempar". Penodaan cara interpretasi (penafsiran makna) pada surah al-Ahzab: 40 "Muhammad itu sekali-kali bukanlah bapak dari seorang lelaki di antara kamu, tetapi dia Rasul dan penutup (khotam)nabi”. Kata 'penutup' dimaknai Ahmadiyah menjadi 'paling mulia', sehingga muncul nabi susulan pasca-Muhammad Saw. Ditandaskan oleh Yaqub, Ahmadiyah berkelit bahwa Mirza Ghulam sebagai mujadid (Yaqub, 2011). Menurut Amidhan Ketua MUI (saat itu) menyatakan bahwa hal mendasar sesatnya JAI (1) Nabi Muhammad diganti Ahmad, (2) Islam turun di India, berhaji tidak di Makkah, (3) muslim selain Ahmadiyah dianggap kafir, (4) jika kita salat di masjidnya, dipel karena dianggap najis, dan (5) Ahmadiyah tidak mau menjadi makmum salat dengan muslim lainnya (Amidhan, 2011). Pernyataan ini perlu didalami karena penulis tidak menemukan pernyataan tersebut dari warga JAI di Kudus. Boleh jadi, hal itu mereka rahasikan, hanya untuk intern JAI. Perihal makmum salat, keengganan warga JAI menjadi makmum salat dengan non-JAI karena non-JAI dianggap warga JAI tidak mengakui keberadaan JAI sehingga tidak perlu berjemaah. Bila salat berjemaah, JAI hanya siap menjadi imam salat. Hal pokok yang rentan menjadi pemicu konflik kaitannya dengan ajaran JAI tentang Imam al-Mahdi dan al-Masih, mujadid, perihal wahyu, kenabian, khilafah, dan jihad (Hasbiyallah \& Syarifudin,
2008). Hal lain yang menggemparkan dengan keluarnya Ahmad Hariadi semula sebagai dai JAI selama sepuluh tahun karena menggugat mubahalah dalam JAI (Hariadi, 2008).

Perlunya pendalaman terhadap kebenaran hal tersebut dan didialogkan. Hukum sebagai panglima sejati berbekal prinsip hukum. Perlunya memahami sebuah ibarat, janganlah mendirikan rumah di dalam rumah seseorang, masih banyak tanah kaveling lain. Maksudnya, bila membawa nama Islam, tentu sesuai aturan Islam. Bila tidak demikian, idealnya dengan besar hati tidak membawa nama Islam, seperti Muhammad Saw adalah nabi dan tidak ada estafet kenabiannya. Tekanan dan ragam upaya untuk memadamkan gerakan Ahmadiyah, tetapi, Ahmadiyah masih eksis, termasuk di Kudus yang oleh publik mendapat julukan kota santri.

Keberadaan JAI secara nasional memiliki tidak kurang 339 cabang (tingkat kabupaten/kota). Syarat mendirikan cabang minimal terdapat 3 jiwa warga Ahmadiyah. Ketiganya dapat menduduki jabatan struktural sebagai ketua, sekretaris, dan bendahara. Ahmadiyah di Jawa Tengah cabangnya terbagi atas Jateng I meliputi Kabupaten Purwokerto, Tegal, Banyumas, Kebumen, Cilacap, dan Brebes. Jateng II di Kabupaten Banjarnegara dan Wonosobo, Jateng III di Kabupaten Batang, Kendal, Semarang, Salatiga, Solo, Magelang, Temanggung, Pati, Rembang, dan Grobogan/Purwodadi, dan Kudus.

Surah Keputusan Bersama (SKB) Nomor 3 Tahun 2008 dan Nomor 199 Tahun 2008 tentang peringatan dan perintah kepada penganut JAI. Isi SKB (1) memberikan peringatan dan memerintahkan warga masyarakat untuk tidak menceritakan, menganjurkan, atau mengusahakan dukungan umum, melakukan penafsiran tentang agama yang dianut di Indonesia atau melakukan kegiatan agama yang menyerupai kegiatan keagamaan dari agama itu yang menyimpang dari pokok-pokok ajaran agama, (2) memberikan peringatan dan memerintah penganut anggota dan pengurus JAI sepanjang mengaku beragama Islam untuk menghentikan penyebaran penafsiran dan kegiatan yang menyimpang dari pokok ajaran agama Islam, yaitu penyebaran paham yang mengaku adanya nabi dengan segala ajarannya setelah Nabi Muhammad, (3) penganut anggota dan pengurus JAI yang tidak Intizar, Vol. 25, No. 1, Juni 2019 
mengindahkan peringatan dan perintah sebagaimana yang dimaksud dalam diktum ke-1 dan ke-2 dapat dikenai sanksi sesuai dengan ketentuan peraturan perundang-undangan, termasuk organisasi dan badan hukumnya, (4) memberikan peringatan dan memerintah warga masyarakat menjaga dan memelihara kerukunan umat beragama serta ketenteraman dan ketertiban kehidupan bermasyarakat dengan tidak berbuat atau bertindak melawan hukum terhadap penganut anggota dan anggota pengurus JAI, (5) warga masyarakat yang tidak mengindahkan peringatan dan perintah sebagaimana dalam diktum ke-1 dan ke-4 dapat dikenai sanksi sesuai dengan ketentuan peraturan perundang-undangan, termasuk organisasi dan badan hukumnya, dan (6) memerintah aparat pemerintah dan pemda untuk melakukan langkah-langkah pembinaan dalam rangka penanganan dan pengawasan pelaksanaan SKB ini. Kriteria tersebut oleh sebagian komunitas akademik/peneliti/pemerhati HAM mendapatkan kritik, bahwa pencetus kriteria adalah manusia (antara elemen yang menerima dengan yang memproduksi adalah sesama manusia), sehingga ketika memahami wahyu memiliki derajat yang sama, kebenaran kriteria adalah kebenaran manusiawi, bukan kebenaran Ilahi (Romli, 2007).

Dari segi perundang-undangan, terdapat pihak yang kontra SKB dengan dalih, pertama, dalam tata perundang-undangan, SKB atau fatwa bukan salah satu struktur hukum positif sebagaimana diamanatkan UU Nomor 10 Tahun 2004, sehingga SKB merupakan cermin inkonsistensi pemerintah (Haris, 2008). Kedua, SKB bertolak belakang dengan Pasal 29 UUD 1945 tentang HAM Pasal 28 E disebutkan setiap orang bebas memeluk agama dan beribadat menurut agamanya (ayat 1) dan berhak atas kebebasan meyakini kepercayaan, menyatidakan pikiran dan sikap sesuai dengan hati nuraninya (ayat 2). Argumen ini perlu didiskusikan lebih lanjut karena kebebasan dalam UU Nomor 39 Tahun 1999 tentang HAM Pasal 73 bahwa kebebasan dibatasi dengan UU. Pada tahun 2005, pemerintah RI meratifikasi kovenan PBB mengenai hak-hak sipil politik diakomodasi dalam UU Nomor 12 Tahun 2005 khususnya pada Bab III Pasal 18 (Latif, 2008). Ketiga, dengan diterbitkannya SKB, Dewan HAM
PBB pada 10 Juni 2008 meminta penjelasan perwakilan Indonesia dalam sidang pleno ke-8 Dewan HAM PBB di Palais de Nations, Jenewa, Swiss. Klarifikasi tersebut karena kebebasan beragama merupakan salah satu hak yang disebut sebagai universal inaliable (tidak bisa dilenyapkan), involable (tidak dapat diganggu gugat), dan nonderogable human rights (hak-hak asasi yang tidak boleh dilanggar) (Ibrahim, 2008).

Selain adanya SKB, ada pula fatwa Majelis Ulama Indonesia (MUI) tentang pelarangan JAI. Hanya saja, terdapat dua kelemahan dalam fatwa. Pertama, fatwa diberi judul Ahmadiyah Qadian, bukan Lahore. Tetapi, dalam batang tubuh fatwa terkadang menggunakan kata Ahmadiyah Qadian, kadang Ahmadiyah saja. Kedua, fatwa ditandatangani 01 Juni 1980/17 Rajab 1400 H pada diktum pertimbangan sebagai rujukan keputusan rakernas MUI pada 4-7 Maret 1984/1-4 Jumadil Akhir 1404 H. Artinya, mungkinkah surah dan fatwa dibuat dengan merujuk pada rekomendasi dan keputusan yang empat tahun setelahnya baru ada? (Alniezar, 2018).

Faktor munculnya aliran sesat menurut Mahally disebabkan oleh tiga hal yakni kurangnya perhatian tokoh agama, penggagas aliran sesat mencari popularitas dan keuntungan pribadi, dan boleh jadi muncul sebagai grand design pihak asing untuk menghancurkan akidah umat Islam. Pernyataan yang ketiga ini direspon oleh Pradana bahwa pernyataan tersebut tidak pernah terbukti secara konkret dan otentik tentang sinyalemen tersebut (Mahally, 2007). Selanjutnya dalam analisis Pradana, bahwa munculnya aliran sesat menurut Peter Clarke diakibatkan oleh gerakan protes yang dilakukan oleh gerakan sempalan terhadap hegemoni kelompok agama mainstream yang berkolaborasi dengan kekuatan politik yang berusaha memonopoli kehidupan agama suatu masyarakat dalam memberlakukan sistem kepercayaan dan praktik keagamaan mereka. Jika analisis itu benar, hendaknya Islam mainstream sepatutnya melakukan introspeksi atas doktrin, kepercayaan, praktik keberagamaan, dan dakwah yang selama ini tidak lagi mampu menarik audiens (Boy, 2007).

Proses pemaknaan Islam melahirkan dua pihak penting yakni pihak utama (ortodoksi/mainstream) 
dan pihak pinggiran. Pihak utama mengacu paham keagamaan yang dianut oleh mayoritas umat, sedangkan pihak pinggiran (sempalan/splinter) diidentikkan dengan ajaran yang keluar dari arus utama sehingga dianggap sesat dan menyesatkan. Sedangkan klasifikasi gerakan sempalan dalam analisis Bryan Wilson bahwa tipologi sempalan terbagi atas tujuh sekte, pertama, sekte conversionist, yang memerhatikan perbaikan moral individu. Kedua, sekte revolusioner, menghendaki perubahan masyarakat secara radikal. Ketiga, introversionis, untuk transformasi dunia yang ditujukan hanya pada kelompoknya. Keempat, manipulationist/gnostic, identik dengan introversionis, akan tetapi adanya proses inisiasi (tapabrata). Kelima, thaumaturgical, tipologi sempalan dengan model penguasaan alam gaib. Keenam, sekte reformis, usaha mereformasi sosial (umat). Ketujuh, gerakan utopian, menciptidakan komunitas sebagai teladan untuk sesama (Zara, 2007).

\section{Strategi Adaptif JAI di Kudus}

Untuk mempertahankan komunitas JAI, warga JAI di Kudus melakukan strategi sebagaimana konsep empat fungsi sistem tindakan versi Talcott Parsons yakni adaptasi, mencapai tujuan (goal attainment), integrasi, dan latency (memelihara pola interaksi) (George \& Goodman, 2003). Keempat fungsi tersebut dilakukannya dengan melibatkan diri pada tradisi warga mayoritas setempat (NU) seperti mengikuti jemaah rutin warga muslim dalam acara pembacaan ayat suci Alquran (surah Yasin) dan pembacaan tahlil. Dengan melakukan keempatnya, eksistensi JAI di Kudus mampu bertahan, kecuali terdapat aksi provokasi yang datang dari warga luar desa Colo di mana JAI eksis.

JAI di Kudus terorganisasi dan mayoritas jemaatnya berada di RT. 3 RW. 3, Dukuh Pandak, Desa Colo, Kecamatan Dawe, Kabupaten Kudus Jawa Tengah sejak 1999 dan menjadi cabang Ahmadiyah ke-288. Data yang diperoleh, JAI awal mula eksis di Kudus tahun 1950-an tapi penulis belum memperoleh data utuh, sehingga perlu pendalaman. Pada tahap awal agar benih keahmadiyahan tumbuh maka dilaksanakan salat Jumat di rumah Ratno, warga JAI. Berikutnya dibangunlah Masjid JAI di Muria Kudus tahun 1999.
Keberadaan JAI di Kudus ditopang peran Nanang Al-Mahdi; semula lahir dan besar di desa Gabus, Kabupaten Pati (tetangga Kudus). Sejak kecil, Nanang menjadi JAI karena orang tua dan saudaranya JAI. Setelah berkeluarga, pekerjaannya di perusahaan di Kudus dan berumah tangga di wilayah Kecamatan Jati Kabupaten Kudus, bukan bertetangga di Colo, tempat sekretariat JAI Kudus. Ia diberi amanah menjadi Ketua Cabang (organisasi tingkat kabupaten) JAI Kudus.

Tradisi Muslim di Kudus yang tidak ditradisikan Ahmadiyah yakni pembacaan manaqib (biografi syekh Abdul Qadir Jailani), pembacaan Maulid Nabi (sejarah Nabi Saw), ziarah kubur, haul (peringatan tahunan wafatnya leluhur) karena Ahmadiyah memurnikan ajaran Islam, yakni melaksanakan Islam yang hanya yang diajarkan Nabi Saw. Akan tetapi, sebagai upaya bergabung dengan muslim setempat, warga JAI Kudus mengikuti kegiatan keagamaan NU tersebut di kampungnya, meski tidak menjadi tradisi JAI. Perempuan JAI Kudus mengikuti kegiatan muslimah setempat (nonJAI) setiap Jumat sekali (perkumpulan rutin di kampungnya). Sebagian lelaki JAI mengikuti kegiatan muslim setempat setiap kamis malam Jumat sekali (pengajian di kampungnya). Selain itu, untuk mempunyai nilai tawar politik, warga JAI Kudus meraih kedudukan politik di desanya. Pada 25 September 2014 ada yang mencalonkan diri pada pemilihan Ketua RW 3 Desa Colo. Dari 353 pemilih, warga JAI hanya mendapatkan 79 suara, pesaingnya dari muslim NU meraih 87 suara, disusul pesaing lainnya mendapat 97 suara, 45 suara, dan 48 pemilih tidak hadir. Di antara alasan warga yang tidak memilih warga JAI sebagai Ketua RW karena keanggotaan calon dari JAI. Akan tetapi, ada warga JAI Kudus yang terpilih menjadi anggota BPD Desa Colo hingga ditulisnya naskah ini.

Pengurus JAI di Kudus dalam mempererat ikatan emosional dan memberikan pemantapan psikisnya dilakukan aktivitas. Pertama, temu berkala rutin tahunan (jalsah salanah) sebagaimana pada 2014 dilaksanakan di Desa Krucil Kabupaten Banjarnegara, Jawa Tengah, penulis menghadirinya. Kedua, aktivitas mengaji Alquran bagi usia anak yang diasuh oleh ustad Ahmadiyah (tatkala riset dilakukan penulis, agenda itu tidak berjalan). Ketiga, 
untuk ibu-ibu dilaksanakan pertemuan rutin bulanan (mu'awanah) yang diselenggarakan di rumah warga Ahmadiyah Kudus secara bergiliran. Kadang kala gabungan dengan JAI asal Gabus Kabupaten Pati. Keempat, mengikuti kegiatan JAI, yakni bagi lelaki mengikuti jemaah salat Jumat di masjid JAI Kudus, bagi perempuan menghadiri kegiatan temu rutin perempuan JAI, bagi lelaki dan perempuan membesuk bila jemaat sakit di rumah sakit atau di rumah. Urat nadi penggerak hingga eksisnya JAI di Kudus selain sosok seorang sesepuh tersebut adalah kiprah mubalig JAI utusan dari JAI Pusat yang difasilitasi perumahan sederhana bersebelahan dengan masjid Ahmadi.

Strategi adaptif yang dilakukan warga JAI di Kudus berimbas tidak terjadi konflik terbuka. Hal ini memiliki beberapa faktor. Pertama, warga Kudus tidak fanatik terhadap Ahmadiyah, meski dipantau geraknya oleh tokoh muslim setempat dengan pernyataan "Warga Ahmadiyah dibohke" (Ahmadiyah dibiarkan saja, tidak diganggu dan tidak diikuti). Kedua, terpicu konflik bila JAI di Kudus menyebarkan ajarannya secara terbuka. Ketiga, ada peluang terjadi konflik bila tersulut oleh pihak tertentu yang tertuju pada warga minoritas. Hal ini didukung dengan gencarnya pemberitaan media massa. Dapat pula dipicu oleh sikap fanatik atas dorongan penggerak aksi. Padahal respon negatif warga Kudus yang keberadaannya bukan di wilayah JAI Kudus yakni adanya pemanfaatan tempat hunian untuk gereja atau gereja yang tidak berizin. Akan tetapi, gereja yang berada di lingkungan JAI Colo pun tidak mendapat respon negatif muslim setempat, meskipun ibadah di gereja tersebut tidak terbuka. Keempat, warga Ahmadiyah tidak menjadi pelaku tindak pelanggaran norma hukum, agama, dan norma sosial sehingga direspon oleh masyarakat sekitar Ahmadiyah Kudus yang lebih mengedepankan aspek tepo seliro. Kelima, adanya ikatan persaudaraan, pertemanan, dan pertetanggaan antara warga JAI dengan non-Ahmadiyah di lingkungannya, sehingga pemicu konflik terminimalisasi secara alamiah. Kelima faktor tersebut sangat ditopang aksi JAI di Kudus yang memenuhi fungsi empat sistem tindakan versi Parsons yakni melakukan adaptasi budaya dengan jemaah Nahdliyin sehingga tujuan eksis tercapai (survive), melakukan integrasi dan Intizar, Vol. 25, No. 1, Juni 2019 memelihara pola interaksi sosial yang positif dengan warga mayoritas setempat.

Untuk mewujudkan eksisnya JAI, ragam upaya dilakukan oleh pengurus pusat JAI dengan penerbitan buletin khotbah, majalah Sinar Islam, website, dan Muslim Television Ahmadiyya (MTA) yang diakses oleh warga JAI se-Indonesia (Said, 2018). Ada pula gerakan kemanusiaan yakni donor darah, donor mata, humanity first (penanganan korban bencana alam), dan clean the city (kebersihan lingkungan pascaperayaan tahun baru) (Rohmawati, 2018).

\section{Faktor Kerukunan JAI dengan non-JAI di Kudus}

Faktor yang menjadi pendukung terwujudnya kerukunan warga Desa Colo antara JAI dengan nonJAI adalah, Pertama, kondisi kehidupan sosial warga Desa Colo kondusif karena sumber ekonomi stabil. Sumber perekonomian warga Desa Colo adalah (1) pedagang yang menjajakkan dagangan bagi wisatawan/peziarah yang menghadiri/berziarah ke Makam Sunan Muria dan makam Syekh Syadzali di Gunung Muria, (2) sebagai petani padi, tebu, perkebunan/peladang kopi, jeruk pamelo, kunir, ketela pohon, dan sebagainya, (3) peternak lebah madu, (4) tukang ojek sepeda motor untuk peziarah/wisata ritual, (5) buruh, dan sebagainya. Kedua, antar-umat dan intern-pemeluk agama keduanya saling membaur dalam aktivitas seharihari di berbagai bidang kehidupan secara bersamasama, seperti di lahan perekonomian, kerja bakti di kampung, dan perkumpulan sosial tingkat RT. Ketiga, warga Desa Colo tidak mudah tersulut konflik karena mengutamakan kerukunan hidup sosial dan beragama didukung oleh harmonisnya kehidupan sosial. Hal ini merupakan karakter kehidupan di pedesaan. Meskipun adanya pernyataan tokoh muslim non-Ahmadi setempat bahwa eksisnya JAI di Colo sangat tergantung pada sosok sesepuh JAI Kudus yang status ekonominya level menengah dibanding warga sekitarnya. Bisnis sampingannya di bidang penjualan air gunung yang dipasarkan dengan mobil tengki mengerjakan sopir dan kernet yang sebagian juga warga JAI Kudus. Selain menjadi pegawai Dinas Pariwisata Kabupaten Kudus, khususnya menangani retribusi lahan wisata 
Makam Sunan Muria. Keberadaan area retribusi, rumah, dan Masjid Ahmadi berada pada satu kawasan. Bila sesepuhnya tidak optimal, diduga JAI tidak akan eksis. Keempat, proaktif terhadap kebijakan pemerintah dan taat terhadap norma sosial yang berlaku di lingkungannya. Kelima, tempat tinggalnya bergabung dengan warga non-Ahmadi, dan keenam terjalinnya interaksi dalam hal kesejahteraan sosial, sebagaimana pembagian daging kurban oleh warga JAI pada warga non-Ahmadi.

Selain hal di atas, adem-ayemnya JAI di Desa Colo karena (1) jumlah pemeluknya hanya 11 kepala keluarga dari 4 ribu jumlah penduduk Desa Colo, (2) warga JAI Kudus tidak melanggar norma sosial, hukum, dan agama dalam kehidupannya, (3) mengadakan kegiatan keagamaan (pengajian umum) yang mengundang warga non-Ahmadi, meski tidak direspon, (4) refleksi keagamaan masyarakat Desa Colo tidak merespon fatwa MUI yang memfatwa Ahmadiyah sesat. Akan tetapi, bila terjadi konflik JAI di luar Kudus, warga JAI di Kudus 'bersiaga'. Di sisi lain karena tidak fanatik dan dipicu pemahaman terhadap agama warga tidak semua mendalam, kesibukan sehari-hari 'ditelan' aktivitas ekonomi (pedagang, petani, pengojek sepeda motor, dsb.), bukan karena tingginya rasa toleransi terhadap aliran yang dianggap sesat MUI, (5) tidak adanya ormas Islam bergaris keras di Kudus yang sering menolak secara frontal pada aliran yang dianggap sesat, (6) tokoh agama setempat tidak berperan sebagai lokomotif melawan Ahmadi, dan (7) ada hubungan kekerabatan,tetangga, dan teman antara warga Ahmadi dengan non-Ahmadi di Kudus (Rosyid, 2011).

\section{Peluang Konflik Latin JAI di Kudus}

Tidak terjadinya konflik terbuka antara JAI Kudus dengan warga muslim mayoritas (non-JAI) bukan berarti adem-ayem dalam berinteraksi, tetapi menyimpan api dalam sekam dengan alasan:

Pertama, komunitas Ahmadiyah menyendiri dalam beribadah salat, yakni di masjid Ahmadiyah. Hal ini berpeluang menimbulkan kecurigaan bagi masyarakat di luar komunitas Ahmadiyah yang tidak memahami realitas sebenarnya. Pengajian JAI tersebut tidak memanfaatkan pengeras suara yang terdengar secara luas, hanya terdengar di dalam masjid, tidak seperti warga non-JAI. Sebagaimana azan salat Jumat (bukan karena tidak memiliki speaker) tetapi karena sikap menjaga diri. Kedua, mubalig JAI yang diutus dari Lembaga JAI yang bermarkas di Bogor (Pusat) tidak selalu berbaur dengan warga masyarakat non-Ahmadiyah dan warga Ahmadiyah di lingkungannya, baik dalam kegiatan sosial maupun keagamaan. Ketiga, tokoh Ahmadiyah merupakan tokoh tim sukses pilkades tahun 1998 di Desa Colo yang terkalahkan, sehingga (diduga) masih menyimpan 'masalah politik' dengan tokoh pemenang pilkades (non-Ahmadiyah). Buntut kekalahannya dengan mendirikan jamiyyah (jemaah keagamaan) baru. Akan tetapi, seiring pergantian kepala desa, masalah politik tersebut makin teredam dan jemaah tersebut berhenti dan kini bergabung dengan jemaah warga NU. Keempat, tokoh Ahmadiyah Colo yang juga menjadi PNS Dinas Pariwisata Kabupaten Kudus memiliki usaha air minum dengan empat truk tengki air sehingga berada pada level ekonomi mapan di lingkungannya. Sebagain warga sungkan bila berbuat tidak benar. Hal ini dipicu oleh (rencana) kebijakan Pemerintah Kabupaten Kudus yang menertibkan penjualan air Gunung Muria. Hal ini memungkinkan terjadi konflik latin bila terpicu oleh dinamika sosial setempat. Hal ini bila tidak diantisipasi maka muncul hal yang tidak diinginkan. Kelima, karakter masyarakat Kudus yang sensitif dan fanatik terhadap aliran yang memiliki 'warna' baru, rentan tersulut bila terdapat loko penggerak (Rosyid, 2015).

Ahmadiyah di Kudus memiliki strategi resolusi konflik dengan 'mengamankan' kelompoknya, memberi pemahaman pada publik bahwa alirannya tidak sesat dengan siasat (1) membuat selebaran yang dibagikan pada warga Colo pada 2006 bertuliskan Tuhannya Sama, Nabinya Sama, (2) masjid yang mereka bangun diberi tulisan kalimat Laailaha illallah muhammdurrosulullah, lafal baru muncul setelah 10 tahun berdiri semenjak gejolak JAI di Indonesia.

\section{Kesimpulan}

Keberadaan JAI di Kudus sejak 1999 hingga kini tidak pernah terjadi konflik terbuka dengan muslim (nahdliyin) setempat. Keberadaannya ditopang oleh satu keluarga. Tidak terjadi konflik

Intizar, Vol. 25, No. 1, Juni 2019 
karena, pertama, kehidupan di pedesaan yang lebih mengutamakan aspek pertemanan, pertetanggaan, dan persaudaraan. Kedua, warga JAI di Kudus tidak melanggar norma susila, norma hukum agama dan negara. Ketiga, ajaran Ahmadiyah tidak dipublikasikan pada warga, hanya pada intern jemaat JAI. Keempat, warga JAI melakukan adaptasi budaya dengan lingkungannya. Adapun faktor tetap eksisnya JAI di Kudus karena pertama, peran sesepuh JAI yang kedudukan ekonominya menengah atas sehingga disegani warga sekitar. Kedua, adanya mubalig JAI ditugaskan dari JAI Pusat yang sehariharinya melayani warga JAI Kudus. Ketiga, fanatikme warga JAI terhadap ajaran Ahmadiyah imbas Islam abangan sehingga tidak memiliki daya kritis. Dari paparan tersebut, berpeluang terjadinya konflik latin karena pertama, dalam beribadah/salat Jumat JAI menyendiri hanya dengan warga JAI saja. Kedua, bila terjadi konflik JAI di luar kota Kudus, maka peluang tersulutnya konflik di Kudus sangat besar karena mudahnya warga mengakses pemberitaan melalui media massa. Tindakan preventif selalu dilakukan oleh pemkab Kudus dalam memantau JAI di Kudus seperti memantau pergerakan JAI.

\section{Daftar Pustaka}

Ahmad, M. (2013). Candy's Bowl: Politik Kerukunan Beragama di Indonesia. Harmoni, 12(3), 37-51.

Alniezar, F. (2018). Mengadili Keyakinan, Merampas Kebebasan Persepsi dan Reaksi JAI terhadap Fatwa MUI dalam JAI Konflik, Kebangsaan, dan Kemanusiaan. Yogyakarta: ISAIS UIN Yogyakarta.

Amidhan. (2011). Ahmadiyah. Republika.

Boy, P. (2007, November 9). Kegagalan (Dakwah) Islam Mainstream. Jawa Pos.

Dzahir, I. I., \& Dahri, H. (2008). Ahmadiah Qodianiyah: sebuah kajian analitis. Balai Penelitian dan Pengembangan Agama Jakarta, Badan Litbang dan Diklat ....

George, R., \& Goodman, D. J. (2003). Teori Sosiologi Modern. Jakarta: Kencana.

Hariadi, A. (2008). Mengapa saya keluar dari Ahmadiyah Qadiani: sebuah kesaksian. Bandung: Irsyad Baitus Salam.
Haris, S. (2008). Dilema Pemerintahan Yudhoyono. Kompas.

Hasbiyallah, \& Syarifudin. (2008). Pro-kontra Ahmadiyah. Grafindo Litera Media.

Ibrahim, J. (2008). Perlindungan HAM Vs SKB Ahmadiyah. Jawa Pos.

Latif, Y. (2008). Demokrasi dalam Pasungan. Kompas.

Mahally, A. (2007, November 9). Pemicu Munculnya Aliran Sesat. Republika.

Nadwi, S. A. H. A., Mundzir, T., \& Ranam, S. (2005). Tikaman Ahmadiyah terhadap Islam. Jakarta: Fadlindo Media Utama.

Penyusun, T. (2012). Pendalaman Aqidah Ahmadiyah oleh Komisi VIII DPR RI. Jakarta.

Rohmawati, W. S. A. (2018). Dari Donor Darah ke Clean the City dalam JAI Konflik, Kebangsaan, dan Kemanusiaan. Yogyakarta: ISAIS UIN Yogyakarta.

Romli, M. G. (2007, November 14). Sesatnya Kriteria Sesat. Jawa Pos.

Rosyid, M. (2011). Ahmadiyah di Kabupaten Kudus. Analisa: Jurnal Pengkajian Masalah Sosial Keagamaan, 18(1).

Rosyid, M. (2015). Mendialogkan Ahmadiyah Belajar dari Cikeusik dan Kudus. Kudus: Neratja Press.

Said, M. (2018). Peran Media dalam Proliferasi Ajarah Ahmadiyah Indonesia Konstruksi otoritas, kesalehan, dan militansi dalam JAI Konflik, Kebangsaan, dan Kemanusiaan. Yogyakarta: ISAIS UIN Yogyakarta.

Sulaeman, A., \& Sabandi, E. O. (2014). Klarifikasi terhadap Kesesatan Ahmadiyah dan Plagiator. Kudus: Neratja Press.

Tegal, R. (2011). Polisi Tetapkan Dua Tersangka. Radar Tegal. Retrieved from https://issuu.com/jaelani/docs/9_feb_2011/2

Wahid, S. (2011). Solusi Ideal Soal Ahmadiyah. Kompas.

Yaqub, A. M. (2011). Penodaan Agama. Republika.

Zara, M. Y. (2007). Aliran-Aliran Sesat di Indonesia. Yogyakarta: Banyu Media.

Zulkarnain, I. (2005). Gerakan Ahmadiyah di Indonesia. Yogyakarta: LKis. 